\title{
Notas sobre cortesía/descortesía en Cervantes y Borges
}

Palabras clave: pragmalingüística, cortesía, descortesía, argumentación, análisis

\section{Introducción}

En este artículo el objetivo principal es ver si se pueden aplicar las estrategias de cortesía/descortesía tanto de la novela de Cervantes, Don Quijote de la Mancha, como del relato de Borges, Pierre Ménard, autor del Quijote, autores que tienen como obra en común el Quijote y que compondrá el corpus de este trabajo siguiendo como base un artículo de Haverkate del 2001 (129-148). Todo ello se hará desde la perspectiva de la Pragmalingüística que considera las estrategias verbales índices del comportamiento en la interacción entre, en este caso, los personajes y las posibles aplicaciones del análisis de la conversación.

Somos conscientes de que el volumen de ambos textos es muy dispar y por ello la obra del alcalaíno será analizada en una proporción bastante exigua, pero aun así se espera poder satisfacer las expectativas del estudio ${ }^{1}$. En concreto se

1 A este respecto hay que destacar que muchos estudiosos no consideran la literatura válida a la hora de analizar la lengua de una comunidad sociocultural, ya que hay una clara voluntad estética en los textos. De hecho, lo ficticio de este lenguaje hace que se levanten muchas voces en su contra, algo que no es del todo cierto porque la realidad puede ir mucho más allá de la ficción y muchos actos de habla presentes en la literatura son funcional y estructuralmente tan válidos como puedan ser los que oímos en cualquier conversación. Gutiérrez Ordóñez (20072: 44-47) sostiene que la Pragmática literaria, dentro de la revolución que supuso la Pragmática, significa otra revolución. De hecho la comunicación literaria es mucho más compleja y presenta una serie de singularidades como la existencia de un Principio de Cooperación Literaria, cuyas máximas son diferentes de las de Grice (1975) o la polifonía de los textos; además, dentro del discurso literario operan esencialmente dos grandes 
han seleccionado, dado el espacio a disposición, 7 ejemplos en donde 3 pertenecen a la obra de Cervantes, 3 al ensayo-cuento de Borges y el restante se refiere a la falsa autoría de ambos textos.

Además, ambos textos que a priori pueden parecer muy diferentes tienen sus puntos en común, como el del falso autor apenas mencionado; la numerosísima bibliografía que han generado (máxime la primera) y, que tanto el protagonista como los objetivos de los textos coinciden. Ahora bien, se puede argumentar que aun pareciendo ambos textos idénticos no lo son porque las circunstancias han cambiado y por este motivo hay que interpretarlos de otra manera. Es decir que si, por un lado, la obra cervantina representa la primera novela moderna y polifónica ${ }^{2}$ que ha influido en la narrativa europea, por otro, el ensayo-cuento de Borges revoluciona «la concepción de la lectura y el lector» (Manguel, 2005).

En cuanto al análisis en sí, nos interesa de la obra cervantina sobre todo los diálogos puesto que proporcionan una cuantiosa información sobre el español coloquial de la época y sobre algunas situaciones comunicativas en las que podremos apreciar las citadas estrategias de cortesía/descortesía, tanto de tipo positivo como negativo, dependiendo de si los personajes centran la atención en la imagen social que de ellos se desprende (locutor) o en la del otro (interlocutor) que sería lo que se conoce en la literatura pragmalingüística, como muestra Haverkate, como imágenes egocéntrica y altrocéntrica. Otros términos de la Pragmática que examinaremos en los ejemplos seleccionados serán la argumentación y el uso de algunas figuras retóricas como la ironía, aunque veremos que persigue objetivos diferentes a la Retórica Antigua ${ }^{3}$.

valores como son la verosimilitud y la ficcionalidad; no obstante esta última, junto con la intención estilística, es la más rechazada para admitir los corpus literarios. Pero como bien explica Gancedo Ruiz, ambos argumentos pueden ser refutados y, a pesar de que no todos los textos literarios pueden analizarse, habrá que definir algunos criterios metodológicos que permitan efectuar estos estudios como la verosimilitud histórica y sociolingüística; y simultáneamente habrá que hacer coincidir el tiempo de la historia con el de la escritura, de modo que las intuiciones del autor como hablante sean adecuadas (2016: 162-173).

2 Moderna porque Cervantes reflexiona sobre los géneros novelescos anteriores a este texto y con ellos crea estructuras nuevas a partir de esa reflexión, siendo su referente primordial la novela picaresca (Rey Hazas, 2014). Polifónica, término acuñado por Bajtín en 1936 (1989), porque en su novela Cervantes se enfrenta dialécticamente a distintas ideas del mundo, representadas por diferentes personajes y cuyo cruce dará lugar al realismo moderno.

3 El profesor Pamies Bertrán, durante el debate que siguió a la lectura de la comunicación en el citado Simposio sobre Cervantes y Borges, sugirió que se marcara claramente la desvinculación de la Retórica Antigua si bien, como señala Gutiérrez Ordóñez (2002: 139 140), esta comparte características y objetivos con la Pragmática como son los siguientes: 1) La Retórica es el arte de la persuasión y la Pragmática, por su parte, la considera como 


\section{Marco teórico}

En este punto haremos un pequeño recorrido por la cortesía/descortesía verbal intentando definirlas, así como la argumentación; todo ello desde la Pragmalingüística que se ocupa de analizar los recursos de una lengua para expresar un acto ilocutivo o intencional, que tiene que ver con la fuerza del enunciado y que realiza una función comunicativa como, por ejemplo, afirmar, prometer, etc.

La cortesía verbal inicia sus estudios en los años setenta y ochenta del siglo pasado, sobre todo en lengua inglesa, los cuales examinan aspectos culturales que constituyen representaciones y valores de la sociedad anglosajona, que no siempre son válidos en otras sociedades.

La descortesía verbal, por otro lado, empieza sus investigaciones más tarde, en concreto a mediados de los años noventa, y en ellas el prefijo «des-» se presenta siempre entre paréntesis lo que indica que el término aún no había sido aceptado, si bien el estudio de los fenómenos descorteses son un campo muy fecundo y la bibliografía más reciente ha empezado a estudiar la descortesía en contextos de comunicación virtual, abarcando distintos géneros discursivos digitales, pero que nada tienen que ver con nuestro argumento.

En lo concerniente a la definición de cortesía/descortesía en el Diccionario de la lengua española de la Real Academia encontramos para cortesía: «f. Demostración o acto con que se manifiesta la atención, respeto o afecto que tiene alguien a otra persona» y para descortesía: «f. Falta de cortesía». Ambas definiciones no son muy satisfactorias, especialmente la segunda. Desde otro punto de vista, como señala Haverkate $(1994,13)$ la disyunción «demostración o acto» sería redundante porque toda demostración representa un determinado tipo de acto. Más apropiada es la definición del Diccionario de términos claves de $E L E$ : «conjunto de estrategias conversacionales destinadas a evitar o mitigar

un aspecto de la actividad perlocutiva de la Teoría de la Argumentación; 2) Retórica y Pragmática estudian la influencia de todos los factores del acto comunicativo en el mensaje; 3) Son una disciplina del discurso; 4) Comparten un sistema de valores distinto al de la Gramática porque la tradicional se ocupaba de la corrección y la moderna, de la gramaticalidad, mientras que, Retórica y Pragmática persiguen el éxito de los enunciados; 5 ) La Lingüística se basa, principalmente en la función referencial y se desentiende de las otras funciones, en cambio Retórica y Pragmática las contemplan en sus estudios; 6) Las figuras retóricas son figuras del discurso y; 7) las figuras de contenido, figuras semánticas o tropos no solo han permitido descubrir algunos principios de la Pragmática, sino que han cambiado el rumbo de esta disciplina. Realmente el predominio del enfoque «neorretórico» de la teoría de la relevancia permite explicar figuras como la ironía, hipérbole, lítotes, metáfora, etc. 
las tensiones que aparecen cuando el hablante se enfrenta a un conflicto creado entre sus objetivos y los del destinatario», pero incompleta porque no hay una entrada para descortesía.

En la bibliografía pragmalingüística nos encontramos a autores como Brown y Levinson (1987), Culpeper (1996), Fraser (1980), Goffman (1967), Lakoff (1973) y Leech (1983) que al intentar definir las estrategias corteses o descorteses representan en gran medida los estudios sobre el tema. Haverkate, por su parte, en el artículo ya citado del 2001 (y que servirá de guía de este análisis) se basa a su vez en Brown y Levinson y centra su interés en «aquellas situaciones comunicativas en las que Don Quijote y Sancho Panza sienten necesidad de desarrollar estrategias para expresar cortesía y descortesía, tanto de tipo positivo como negativo» (2001:129).

Con relación a la cortesía, Goffman (1967) se sitúa en primer lugar y aportará al Modelo de Brown y Levinson el concepto de imagen o 'face' que cada individuo tiene de sí mismo y que pone en juego en la interacción social, intentando mantenerla intacta y esperando un reconocimiento por parte de la sociedad.

Fraser (1980) cree que la cortesía verbal se funda en lo que él define como «contrato conversacional» esto es, los derechos y obligaciones que las personas establecen a través de la conversación. Para él una locución es cortés si según el oyente, el hablante no ha violado los derechos u obligaciones vigentes en el momento en que la expresa.

Lakoff (1973) establece dos reglas fundamentales y de este modo se adecúa a la Pragmática: 1) Sea claro; 2) Sea cortés. Leech (1983), en cambio, no establece reglas, sino que propone un principio de cortesía con sus máximas como Grice (1975).

Brown y Levinson (1987), por último, crean un modelo que pretende completar el modelo de Grice, pero sumándole la faceta interpersonal de la que este carecía y que se apoya en dos presupuestos universales que son la racionalidad y la imagen. El primero se ampara en Grice, mientras que el segundo, de origen sociológico, es el citado concepto de imagen de Goffman, ampliándolo un poco más por lo que nos encontramos con el concepto de imagen pública que hay que salvaguardar ya que es vulnerable y, para protegerla, no debemos dañar ni amenazar la de los demás.

En cuanto a la descortesía, Culpeper (1996) compuso una teoría basada en Brown y Levinson que definió como el comportamiento que busca causar 
ofensa y que amenaza voluntariamente el prestigio del otro. Distingue, además, entre una descortesía inherente y una descortesía falsa en la que esta última no pretende ofender, sino mostrar solidaridad social o intimidad y por último opina que el contexto juega un importante papel, lo que significa que no en todas las situaciones se es descortés. En relación con el contexto Leech (1983) habla de descortesía absoluta y relativa. La absoluta es siempre descortés, independientemente del contexto en el que se encuentre; la relativa puede ser o no descortés a partir de un contexto en particular.

Para terminar, la argumentación puede ser entendida desde una perspectiva retórica, que comprende el conjunto de estrategias que organizan el discurso persuasivo, o bien desde una perspectiva lógica, en la que una argumentación es un tipo de razonamiento. En el citado Diccionario de términos clave de ELE la definición abarca ambas perspectivas puesto que, por una parte, es la expresión de un punto de vista razonado a través de una palabra, enunciado o texto, pero, por otra, se persigue influir en la opinión, actitud o comportamiento del destinatario. Anscombre y Ducrot (1983) también estarían en esta dirección porque, para ellos, un emisor hace una argumentación cuando presenta uno o más enunciados para hacer admitir otro u otros enunciados.

\section{Análisis de los textos}

\section{1}

[...] Historia de don Quijote de la Mancha, escrita por Cide Hamete Benengeli, bistoriador arábigo [...] (Don Quijote I, IX: 86).

El método inicial que imaginó era relativamente sencillo. Conocer bien el español, recuperar la fe católica, guerrear contra los moros o contra el turco, olvidar la historia de Europa entre los años de 1602 y de 1918, ser Miguel de Cervantes. Pierre Menard estudió ese procedimiento (sé que logró un manejo bastante fiel del español del siglo diecisiete) pero lo descartó por fácil (Pierre Ménard, autor del Quijote, 447).

El primer ejemplo se refiere a la autoría de El Quijote. En la obra de Cervantes se nos dice que la ha escrito un tal Cide Hamete Benengeli y en la de Borges un tal Pierre Ménard quiere ser Miguel de Cervantes, pero de lo que sí estamos seguros es que ambos son ficticios. 
Esta estrategia literaria lo que pretende es dar mayor credibilidad al texto, algo imposible porque, en el caso del Quijote, este autor genera múltiples incongruencias temporales. Por otro lado, si nos basamos en los estudios sobre cortesía, esta se fundamenta en el concepto de imagen o face de Goffman, a través de la cual los adultos de una sociedad son conscientes tanto de su imagen como de la de los demás y, su objetivo principal, mantenerla intacta; por consiguiente, esconderse detrás de otro, puede querer decir que Cervantes no quería dañar la propia imagen y que adopta esta estrategia del autor ficticio por motivos de censura, etc. recibiendo por ello una imagen positiva, mientras que Cide Hamete Benengeli obtiene, según Gancedo Ruiz (2016: 164), un efecto neutro o autoimagen que no es ni cortesía ni descortesía. Sin embargo, Borges daña la imagen del otro porque se burla de él (muchas personas creyeron que Pierre Ménard era un personaje real) y a su vez se daña a sí mismo porque no se trata de un caso de anonimato, sino que se sabe que fue él, el autor del ensayo-cuento.

En cuanto al principio de cortesía de Leech, algunas de sus máximas poseen factores que minimizan y maximizan, como la de aprobación que maximiza el elogio y minimiza la crítica, pero no de Cide Hamete o de Pierre Ménard, sino de Cervantes y Borges, así como la de modestia que minimiza el autoelogio y maximiza el elogio del otro.

Por lo que se refiere a las figuras retóricas podría pensarse en la parodia porque lo de Borges/Ménard parece una imitación burlesca de la obra del alcalaíno de la que se transcribe solo una ínfima parte.

\section{2}

-Yo os agradezco, señor caballero, el deseo que mostráis tener de favorecerme en mi gran cuita, bien así como caballero a quien es anejo y concerniente favorecer los huérfanos y menesterosos, y quiera el cielo que el vuestro y mi deseo se cumplan, para que veáis que hay agradecidas mujeres en el mundo; y en lo de mi partida, sea luego, que yo no tengo más voluntad que la vuestra: disponed vos de mí a toda vuestra guisa y talante, que la que una vez os entregó la defensa de su persona y puso en vuestras manos la restauración de sus señoríos no ha de querer ir contra lo que la vuestra prudencia ordenare.

-A la mano de Dios -dijo don Quijote-: Pues así es que vuestra señoría se me humilla, no quiero yo perder la ocasión 
de levantalla y ponella en su heredado trono. La partida sea luego, porque me va poniendo espuelas al deseo y al camino lo que suele decirse que en la tardanza está el peligro; y pues no ha criado el cielo ni visto el infierno ninguno que me espante ni acobarde, ensilla, Sancho, a Rocinante y apareja tu jumento y el palafrén de la reina, y despidámonos del castellano y de estos señores, y vamos de aquí luego al punto (Don Quijote I, XLVI, 476-477).

En este caso podemos hablar de cortesía puesto que el mensaje que encierra causa un efecto positivo, pero si lo contextualizamos vemos que la bella Dorotea, autora de tales palabras, poco antes había puesto sobre aviso de que se acomodaba al estilo de don Quijote y por ende se infiere que hay algo detrás de tales palabras. Cervantes a través de una serie de implicaturas positivas nos hace ver su intención, que es mostrarnos la locura de don Quijote, quien confunde la realidad con la ficción al pensar que la venta en que pernoctan es un castillo. Siguiendo con la lectura vemos que todo se aclara y se nos informa de que se trata de un engaño impregnado de ironía ya que todos dicen lo contrario de lo que piensan, salvo el burlado. La ironía suele presentarse como una locución intencionadamente irónica del hablante y hay que interpretarla de esta forma para poder comprender su efectividad comunicativa (Torres Sánchez, 1999:2). En realidad, lo que parecía ser cortés no lo es y como consecuencia la imagen de don Quijote resulta dañada.

\section{3}

Ménard (acaso sin quererlo) ha enriquecido mediante una técnica nueva el arte detenido y rudimentario de la lectura: la técnica del anacronismo deliberado y de las atribuciones erróneas. Esa técnica de aplicación infinita nos insta a recorrer la Odisea como si fuera posterior a la Eneida y el libro Le jardin du Centaure de madame Henri Bachelier como si fuera de madame Henri Bachelier. Esa técnica puebla de aventura los libros más calmosos. Atribuir a Louis Ferdinand Céline o a James Joyce la Imitación de Cristo, ¿̇no es una suficiente renovación de esos tenues avisos espirituales? (Pierre Ménard, autor del Quijote, 450). 
Borges, por un lado, actúa como un narrador testigo enumerando lo que sabe sobre su protagonista y, por otro, nos muestra su gran erudición, que para un lector con poco conocimiento enciclopédico resulta difícil de inferir. $\mathrm{Y}$ es a través de la argumentación, que el argentino intenta influir en los lectores, imponiendo su punto de vista y concluyendo con lo que ha querido decir en este escrito, es decir, revalorizar la imagen del tal Ménard y a su vez la de Cervantes. En su texto hay persuasión y no manipulación, pero desafortunadamente no todos los lectores son capaces de comprender sus palabras por lo que no hay empatía entre ambos. La imagen de este tipo de lector queda dañada porque el conocimiento, que le puede servir como arma no puede utilizarlo, demostrándose vulnerable. Del mismo modo se puede hablar de transtextualidad puesto que se nombran un gran número de obras, que en muchos casos son inventadas.

\section{4}

-Todas estas malandanzas te suceden, empedernido caballero, por el pecado de tu dureza y pertinacia; y plega a Dios que se le olvide a Sancho tu escudero el azotarse, porque nunca salga de su encanto esta tan amada tuya Dulcinea, ni tú lo goces, ni llegues a tálamo con ella, a lo menos viviendo yo, que te adoro (Don Quijote II, XLVI, 899).

En este caso la actitud negativa de la dama hacia don Quijote es porque pretende demostrarle que lo quiere y por ello lo ofende abiertamente, lo agrede en un crescendo donde se palpa la tensión que desemboca no ya en todo lo negativo que le ha deseado, sino en un cumplido: 'yo te adoro'. Hay, pues, una antítesis clara entre lo que desea y verdaderamente siente, pero no puede hablarse de ironía. Por otra parte, lo que empieza como descortés acaba siendo cortés. Ahora bien, la imagen que se presenta aquí es egocéntrica porque la dama no se preocupa para nada de la imagen positiva del oyente-don Quijote y sí de la suya.

\section{5}

La obra visible que ha dejado este novelista es de fácil y breve enumeración. Son, por lo tanto, imperdonables las omisiones y adiciones perpetradas por madame Henri Bachelier en un catálogo falaz que cierto diario cuya tendencia protestante no 
es un secreto ha tenido la desconsideración de inferir a sus deplorables lectores -si bien estos son pocos y calvinistas, cuando no masones y circuncisos. Los amigos auténticos de Ménard han visto con alarma ese catálogo y aun con cierta tristeza. Diríase que ayer nos reunimos ante el mármol final y entre los cipreses infaustos y ya el Error trata de empañar su Memoria... Decididamente, una breve rectificación es inevitable (Pierre Ménard, autor del Quijote, 444).

En este último ejemplo de descortesía se intenta recomponer las omisiones que ha sufrido la obra de Ménard, proponiendo una rectificación a este acto negativo. Por otro lado, podría tratarse del concepto de subjetividad (Fuentes Rodríguez, 2012: 50) con referencia al comportamiento y la relación interactiva. Normalmente no sería admisible expresar nuestras emociones y, dentro de la argumentación, la retórica las rechaza como falaces porque se acercan mucho a la manipulación, al carecer de razones basadas en la lógica. En concreto estamos ante un argumentum ad bominem, que consiste en desacreditar al interlocutor, que en este caso son los lectores de un periódico protestante y a todos aquellos que quieren empañar la memoria del galo.

\section{6}

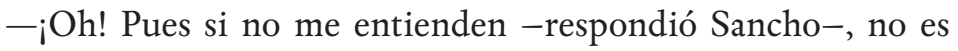
maravilla que mis sentencias sean tenidas por disparates. Pero no importa: yo me entiendo, y sé que no he dicho muchas necedades en lo que he dicho, sino que vuesa merced, señor mío, siempre es friscal de mis dichos, y aun de mis hechos.

-Fiscal has de decir -dijo don Quijote-, que no friscal, prevaricador del buen lenguaje, que Dios te confunda (Don Quijote II, XIX, 693).

En este fragmento Sancho hace autocrítica y le echa en cara a su amo el que siempre esté controlando todo lo que hace o dice. Por otra parte, la falta de cultura de este es uno de los motivos generales, junto con la falta de entendimiento y la prolijidad, que amenazan la personalidad del escudero. Estos actos expresivos amenazan la imagen positiva del interlocutor, Sancho, de manera unilateral; en concreto es censurado por el error lingüístico que comete 'friscal' por 'fiscal' y se le insulta diciéndole 'prevaricador del lenguaje y que Dios te confunda'. El insulto es uno de los actos que requieren que el ofensor se 
disculpe para poder restablecer el balance interaccional entre hablante y oyente (Haverkate, 1994: 99). Es también necesario para comprendernos y superar los estereotipos y nuestras propias ideas y, en este, la función referencial no es lo más importante, sino la enunciación, el tono y el efecto sobre el insultado. $\mathrm{Cu}-$ riosamente pueden ser también jocosos, irónicos o demostrar admiración por alguien (Luque Durán, Pamies Bertrán, Manjón Pozas, 2014: 3, 9, 14).

\section{7}

"Mi propósito es meramente asombroso" me escribió el 30 de setiembre de 1934 desde Bayonne. "El término final de una demostración teológica o metafísica -el mundo externo, Dios, la casualidad, las formas universales- no es menos anterior y común que mi divulgada novela. La sola diferencia es que los filósofos publican en agradables volúmenes las etapas intermediarias de su labor y que yo he resuelto perderlas". En efecto, no queda un solo borrador que atestigüe ese trabajo de años (Pierre Ménard, autor del Quijote, 447).

Este último ejemplo está representado por un acto comunicativo egocéntrico, cuya finalidad es fortalecer la imagen positiva del hablante y no la del oyente (altrocéntrico). Podría tratarse de 'autocortesía', como señala Haverkate, así como que esta categoría no ha atraído a la Lingüística pragmática porque la función básica de la cortesía se interpreta en términos de beneficio para el interlocutor. Lo que no deja de ser curioso es que al final Ménard opte por destruir su obra.

\subsection{Resultados}

Partiendo del modelo de cortesía de Brown y Levinson podemos destacar que el concepto de imagen pública no sale muy bien parado en los ejemplos seleccionados y que predominan los actos comunicativos egocéntricos cuyo objetivo es proteger o fortalecer la imagen positiva del hablante en lugar de la del oyente.

Por otro lado, el objetivo principal del artículo que consistía en ver si se podían aplicar las estrategias de cortesía/descortesía tanto a la novela de Cervantes, como al ensayo-cuento de Borges se ha visto cumplido y, en general, predominan los casos de descortesía. 


\section{Conclusiones}

Si tenemos en cuenta el Principio de Cooperación Literaria, vemos que la verosimilitud se opone a la verdad por lo que ni Cervantes ni Borges infringen este valor, algo que no podríamos defender si se hablara del Principio de Cooperación de Grice dado que en ambos textos se miente en cuanto a la autoría.

En el análisis de las imágenes positiva y negativa de ambas obras hemos centrado la atención en los actos de habla que tipifican la personalidad y los papeles interaccionales de los personajes. En el caso del Quijote los actos expresivos amenazan la imagen positiva de Sancho, sobre todo, en lo referente a la falta de cultura de este. En el ensayo-relato, suele verse dañada la imagen del lector que no siempre está a la altura de las circunstancias.

En la realización de los actos exhortativos predomina el empleo del ruego, pero don Quijote se sirve del mandato cuando quiere hacer valer su autoridad. Por su parte Borges emplea la argumentación sin caer en la manipulación incluso cuando se ve embargado por la emoción.

Para finalizar, este trabajo tiene aún mucho recorrido por hacer y las posibilidades que ofrecen los textos, en especial el Don Quijote de la Mancha, son infinitas.

\section{Bibliografía}

Anscombre, J. C., Ducrot, O. (1983): L'argumentation dans la langue. Bruxelles: Pierre Mardaga éditeur.

Bajtín, M. (1989): Teoría y estética de la novela. Madrid: Taurus.

Borges, J. L. (1984 $\left.4^{14}\right)$ : Pierre Ménard, autor del Quijote» (Ficciones). En: Obras Completas 1923-1972. Buenos Aires: Emecé Editores, 444-450.

Cervantes Saavedra, M. (2004): Don Quijote de la Mancha. Edición del IV Centenario. Madrid: Real Academia Española y Asociación de Academias de la Lengua Española-Alfaguara.

Brown, P., Levinson, S. (1987): Politeness: Some universals in language usage. Cambridge: Cambridge University Press.

Culpeper, J. (1996): «Towards an anatomy of impoliteness». Journal of Pragmatics 25, 3, 349-367.

CVC: Diccionario de términos clave de ELE: http://cvc.cervantes.es/Ensenanza/ biblioteca_ele/diccio_ele/default.htm. 
Fraser, B. (1980): «Conversational mitigation». Journal of Pragmatics 4, 4, 341350.

Fuentes Rodríguez, (2012): «Subjetividad, argumentación y (des)cortesía». Círculo de lingüística aplicada a la comunicación, 49, 49-92.

Gancedo Ruiz, M. (2016): «El texto dramático literario como corpus para el análisis histórico de las actividades de imagen». Textos en Proceso, 2, 1, 162173 .

Goffman, E. (1967): Interactional ritual: Essays on face-to-face behavior. New York: Doubleday.

Grice, H. P. (1975): «Logic and Conversation». En: Peter Cole, Jerry L. Morgan (eds.), Syntax and Semantics, vol. 3: Speech Acts. New York: Academic Press, 41-58.

Gutiérrez Ordóñez, S. $\left(2007^{2}\right)$ : Comentario pragmático de textos. Madrid: Arco/ Libros.

Gutiérrez Ordóñez, S. (2002): De pragmática y semántica. Madrid: Arco/Libros. Haverkate, H. (2001): «Cortesía y descortesía en los diálogos del Quijote. Análisis de la representación de las imágenes positiva y negativa de los protagonistas». Oralia. Análisis del discurso oral, 4, 129-148.

Haverkate, H. (1994): La cortesía verbal. Estudio Pragmalingüístico. Madrid: Gredos.

Lakoff, R. (1973): «The logic of politeness; or, minding your p's and q's». En: Papers from the Regional Meeting. Chicago Linguistic Society: IX, 292-305.

Leech, G. N. (1983): Principles of Pragmatics. London: Longman.

Luque Durán, J.D., Pamies Bertrán, A., Manjón Pozas, F. J. (2014): El arte del insulto. Granada: Granada Lingüística.

Manguel A. (2005): «Herederos de "Pierre Menard, autor del Quijote"», en La Nación, 16 de enero de 2005: http://www.lanacion.com.ar/671434herederos-de-pierre-menard-autor-del-quijote.

RAE (201423): Diccionario de la lengua española. Madrid: Espasa Calpe. http:// www.rae.es/rae.html.

Rey Hazas A. (2014): Entrevista a Antonio Rey Hazas: 01. La novela moderna. Alicante: Biblioteca Virtual Miguel de Cervantes: http://www.cervantesvirtual.com/nd/ark:/59851/bmcfb6x5.

Torres Sánchez, Ma A. (1999): Aproximación pragmática a la ironía verbal. Cádiz: Universidad de Cádiz. Servicio de Publicaciones. 
María Sagrario del Río Zamudio

University of Udine

\section{Notes on politeness and impoliteness in Cervantes and Borges}

Keywords: pragmatics, politeness, impoliteness, argumentation, analysis

The main objective of this article is to outline an analysis of verbal politeness and impoliteness based on selected passages of El Quijote and Borges' story Pierre Ménard, autor del Quijote. Through the lens of these texts, we were able to examine some of the different theories that have emerged on this topic, and, in particular, certain politeness strategies. In our discussion we consider both the rhetorical perspective (which encompasses strategies for creating persuasive discourse), and the logical perspective, basing our arguments on specific examples in the texts. The results of this analysis lead to the conclusion that verbal politeness offers a frame of reference which enables a better understanding of the texts in question, opening up new perspectives not considered by traditional literary theory. Further, we observed that not everything that initially appeared impolite, and even offensive, actually was impolite, and vice versa. 
María Sagrario del Río Zamudio

Univerza v Vidmu

\section{Zaznamki o vljudnosti in nevljudnosti pri Cervantesu in Borgesu}

Ključne besede: pragmatično jezikoslovje, vljudnost, nevljudnost, argumentacija, analiza

Pričujoči prispevek si na podlagi odlomkov iz Don Kibota in Borgesove kratke zgodbe Pierre Ménard, avtor Kihota prizadeva predvsem analizirati jezikovno vljudnost in nevljudnost. Odlomki omenjenih besedil so avtorici služili za proučevanje nekaterih izmed vrste različnih teorij o vljudnosti, še posebej pa nekaterih vljudnostnih strategij. Avtorica se je pri argumentiranju oprla tako na retorični vidik, $s$ katerega je podrobno proučila strategije, ki urejajo prepričevalni diskurz, kot tudi na stališča logike, ki na podlagi sklepanja omogoča utemeljitev nekaterih primerov. Rezultati analize kažejo, da jezikovna vljudnost dovoljuje vzpostavitev referenčnega okvirja, ki z odpiranjem novih vidikov, neupoštevanih $\mathrm{s}$ strani tradicionalne literarne teorije, prispeva $\mathrm{k}$ boljšemu poznavanju obeh analiziranih besedil. Poleg tega avtorica opaža, da ni vse, kar se na prvi pogled zdi nevljudno ali celo žaljivo, vedno takšno tudi $\mathrm{v}$ resnici in obratno. 